\title{
In defense of abstractionist theories of repetition priming and word identification
}

\author{
JEFFREY S. BOWERS \\ University of Bristol, Bristol, England
}

\begin{abstract}
There is a great deal of interest in characterizing the representations and processes that support visual word priming and written word identification more generally. On one view, these phenomena are supported by abstract orthographic representations that map together visually dissimilar exemplars of letters and words (e.g., the letters $A / a$ map onto a common abstract letter code $a^{*}$ ). On a second view, orthographic codes consist in a collection of episodic representations of words that interact in such a way that it sometimes looks as if there are abstract codes. Tenpenny (1995) contrasted these general approaches and concluded by endorsing the episodic account, arguing that no evidence demands that we posit abstract orthographic representations. This review reconsiders the evidence and argues that a variety of priming and nonpriming research strongly supports the conclusion that abstract orthographic codes exist and support priming and word identification. On this account, episodic representations are represented separately from abstract orthographic knowledge and contribute minimally to these functions.
\end{abstract}

There is a great deal of interest in characterizing the representations and processes that support the improved processing of stimuli repeated during an experiment - the repetition priming effect. Indeed, two different types of repetition priming have been intensively studied from two quite different perspectives. On the one hand, researchers interested in memory have tended to focus on long-term repetition priming, in which facilitation can last minutes, hours, and sometimes longer (Sloman, Hayman, Ohta, Law, \& Tulving, 1988). For example, participants are generally faster and more accurate in making lexical decisions to test words encoded a few minutes or hours previously in a study list (see, e.g., Scarborough, Cortese, \& Scarborough, 1977). On the other hand, researchers interested in language processing have tended to focus on short-term repetition priming in order to address questions regarding how single words are identified. In a typical short-term priming task, a pattern mask (e.g., \#\#\#\#) is replaced by a prime word that is briefly flashed (e.g., $50 \mathrm{msec}$ ), which in turn is replaced by the target. Under these conditions, primes are typically unnoticed by the participants, but these items nevertheless facilitate processing of targets when the prime and target are the same. One key attribute of masked priming is that it lasts only a few seconds (e.g., Forster \& Davis, 1984).

Among memory researchers, interest in long-term repetition priming was inspired by the observation that densely amnesic patients show robust (sometimes normal) priming despite poor (sometimes chance) performance

I thank Chad Marsolek, Michael Masson, Kate Nation, and Keith Rayner for valuable suggestions that greatly improved this paper. Correspondence should be addressed to J. S. Bowers, Department of Experimental Psychology, University of Bristol, 8 Woodland Road, Bristol BS8 1TN, England (e-mail: j.bowers@bris.ac.uk). on explicit recall and recognition tests (Warrington \& Weiskrantz, 1974). These findings led to important claims regarding the nature of amnesia, and more generally, opened up memory research to the experimental study of "unconscious" or "implicit" memory. Later work demonstrated various dissociations between long-term priming and explicit memory in persons with unimpaired memories. For example, priming is not generally facilitated by levels-of-processing manipulations (e.g., Graf \& Mandler, 1984; Jacoby \& Dallas, 1981), whereas recognition and recall are highly sensitive to these procedures (Craik \& Tulving, 1975). In addition, changes in the modality of study-test items reduce or eliminate priming (e.g., Jackson \& Morton, 1984; Jacoby \& Dallas, 1981), whereas these manipulations have little effect on recognition (e.g., Roediger \& Weldon, 1987). The latter two dissociations led to the common view that priming is largely mediated by perceptual memory representations - at least when priming is assessed in tests that stress the perceptual processing of single words, data-driven priming tasks (e.g., Blaxton, 1989). The conclusion that perceptual codes mediate long-term priming is further supported by the null priming obtained between synonyms (e.g., Roediger \& Challis, 1992) or between translation equivalents in bilingual speakers (e.g., Kirsner, Smith, Lockhart, King, \& Jain, 1984), as well as the severely reduced priming obtained between pictures and their corresponding names (e.g., Rajaram \& Roediger, 1993; but see Masson \& Freedman, 1990; Masson \& MacLeod, 1992, for an argument that long-term priming is mediated by semantic representations in data-driven tasks).

In this tradition, long-term priming is generally thought to be the product of new perceptual representations acquired during an earlier study episode (Roediger \& Blaxton, 1987; Schacter, 1990; Tulving \& Schacter, 
1990)-what Tenpenny (1995) called episodic theories of priming. The primary question of interest has been to relate theories of priming to theories of recall and recognition. Indeed, one of the central debates that has emerged from this perspective is whether priming and explicit memory can be explained within a single memory system, or whether qualitatively different memory systems need to be proposed.

By contrast, short-term repetition priming was first introduced as a tool to study the identification processes that support single word reading (e.g., Evett \& Humphreys, 1981; Forster \& Davis, 1984). One of the goals of introducing this procedure was to insulate identification processes from the episodic influences that were presumed to mediate long-term priming (Forster \& Davis, 1984). Instead of asking questions regarding memory, shortterm priming was used to ask questions regarding the visual format of word representations (e.g., Humphreys, Evett, \& Quinlan, 1990), whether and how morphological relations are coded in the orthographic and related systems (e.g., Forster, Davis, Schoknecht, \& Carter, 1987; Grainger, Cole, \& Segui, 1991), the nature of the interactions among lexical-orthographic codes (e.g., Forster et al., 1987; Segui \& Grainger, 1990), and whether phonological codes are automatically contacted during visual word identification (e.g., Grainger \& Ferrand, 1994; Lukatela \& Turvey, 1994), among other questions.

The typical conclusion derived from this literature is that the orthographic representations supporting this priming are coded in an abstract format along various dimensions, such that different letter (e.g., $A / a / a$ ) and word (e.g., READ/read/READ) exemplars map onto common abstract orthographic representations (Bowers, Vigliocco, \& Haan, 1998; Humphreys et al., 1990), and morphological variants of a word contact common abstract root morphemes (Forster et al., 1987). From this perspective, the task of visual word identification is to reduce or eliminate the perceptual variability associated with inputs in order to map these inputs onto abstract lexicalorthographic representations, much like traditional theories of spoken word processing, in which the perceptual representations of phonological segments, phonemes, syllables, and so on, are coded in a format that does not encode the surface details of the inputs (e.g., Liberman, 1970; Liberman \& Mattingly, 1985). Such views of shortterm priming and word identification have been labeled abstractionist by Tenpenny (1995), since the orthographic (and phonological) representations supporting these processes are assumed to abstract away from the specific information associated with particular words encoded in prior episodes.

Although studies of long- and short-term repetition priming have generally been carried out independently in the memory and language fields, respectively, there has been some overlap in the literatures from the beginning. For example, Morton (1979) and Jackson and Morton (1984) used long-term priming in order to address questions about visual and spoken word identification, and based in part on these findings, developed an abstractionist model of word perception. More recently, a number of authors, including Biederman and Cooper (1991), Bowers and Michita (1998), and Ratcliff and McKoon (1997), have also employed long-term priming techniques to study word and object perception, adopting abstractionist perspectives.

Similarly, long-term priming results have also been used to support episodic theories of word and object identification (see Tenpenny, 1995). From this perspective, the visual and phonological representations used in word and object identification are the product of all the past exposures to these stimuli, and episodic traces of specific words continue to be represented within the visual and phonological systems. On some views, the different episodic instances are merged together over many trials within connectionist systems (e.g., McClelland \& Rumelhart, 1986; Seidenberg \& McClelland, 1989); on other views, all of the instances are coded independently and separately from one another (e.g., Goldinger, 1998; Hintzman, 1986). In either case, visual and phonological "prototypes" are the emergent properties of a large set of highly specific traces that interact in such a way that it sometimes looks as if there are abstract codes.

In a timely article, Tenpenny (1995) explored the links between these two literatures by providing a thorough review of the repetition priming research relevant to the question of whether words are identified through the use of abstract lexical representations, specific episodic representations, or both. Although Tenpenny was primarily concerned with long-term priming, she also discussed shortterm effects as she attempted to provide a unitary account of these priming and word identification processes. On the basis of this review, she endorsed the idea that episodic memory codes mediate word identification and priming, and argued that "there is no clear evidence that abstract representations are used at all, and it may be possible to account for the data without them" (pp. 359-360).

Although Tenpenny (1995) achieved the worthwhile goal of linking the two priming literatures, there are other ways in which the data can be interpreted. In the first section of this review, I argue that the various priming results Tenpenny cited in support of the episodic approach can readily be interpreted within an abstractionist framework. Indeed, a number of additional priming results are described that are difficult to explain from an episodic perspective, but that are predicted on abstractionist theories. In a second section, a variety of nonpriming results are also described that support abstractionist views, but that are difficult to accommodate with episodic theories. On the basis of these considerations, I defend a weakly abstractionist approach (see Tenpenny, 1995), in which preexisting abstract word codes typically mediate word identification and repetition priming phenomena, but in which episodic traces can contribute to these functions under some circumstances. In the third and final section, I conclude by outlining the types of abstractionist theories that seem the most promising. 


\section{REVIEW OF THE PRIMING RESULTS}

Tenpenny (1995) organized her review of the priming evidence relevant to the abstractionist/episodic debate into four main sections - studies that assessed (1) the longevity of priming, (2) the influence of various contextual variables on priming, (3) word-pseudoword differences in priming, and (4) morphological constraints on priming. In this first section, I maintain this structure, dealing with these findings in turn.

\section{The Longevity of Repetition Priming}

Two qualitatively different forms of repetition priming that have very different time courses need to be distinguished. As noted, short-term priming tends to last only a few seconds (e.g., Forster \& Davis, 1984) and is generally interpreted within abstractionist theories, according to which priming reflects the activation of abstract orthographic codes (e.g., Grainger \& Ferrand, 1994) or the temporary opening of abstract lexical entries (e.g., Forster \& Davis, 1984). Although Tenpenny (1995) did not endorse these interpretations of short-term priming, she conceded that the short-lived nature of this priming is compatible with abstractionist approaches.

Long-term priming, however, can persist for minutes, hours, and sometimes longer (e.g., Jacoby \& Dallas, 1981; Roediger, Weldon, Stadler, \& Riegler, 1992; Sloman et al., 1988). According to the abstractionist approach, this priming reflects structural changes to orthographic representations, which in turn affects the later processing of repeated items. For example, in Morton's (1979) logogen model, long-term priming is explained as the lowering of the word's threshold so that less activation is required to identify the word when it is repeated. Note that the structural change that is presumed to mediate longterm priming is different from the temporary activation of preexisting orthographic codes (or opening of lexical entries) that is presumed to mediate masked priming.

According to Tenpenny (1995, p. 342), however, longterm effects pose a serious problem to abstractionist views, because "hundreds or thousands" of abstract word codes would necessarily be primed given that the typical person reads many words each day, and this is considered an "implausibly" large set of words. This problem is thought to become even more acute if an abstractionist model incorporates competition among lexical units, as assumed by various theorists (e.g., Grainger \& Ferrand, 1994; McClelland \& Rumelhart, 1981). The argument here is that many words are identified between the presentation of the prime and target, and these intervening words should eliminate any priming due to the interference that results from lexical competition. On the basis of these considerations, Tenpenny argued that episodic traces must be mediating these long-lasting effects, and perhaps the short-term priming effects as well.

However, rejecting abstractionist theories on the basis of the longevity of long-term priming is unwarranted, for a number of reasons. First, the sheer number of words that the typical person reads during the day does not preclude priming even if all read words are automatically primed. Kirsner and Speelman (1996) noted that if a person reads 25,000 words a day, a low-frequency word with a frequency count of one per million would be encountered only once every 40 days! Accordingly, low-frequency words are unlikely to have been read (and primed) just prior to the experimental setting, and thus there is no reason to presume that these items cannot benefit from repetition within an experiment, even if the delay is a few minutes, hours, or days. Consistent with this interpretation, priming for high-frequency words is much reduced relative to that for low-frequency words, and occasionally, priming for high-frequency words is absent altogether (e.g., Bowers, 1999b; Forster \& Davis, 1984; Rajaram \& Roediger, 1993).

In addition, there is no reason to presume that these structural changes occur automatically each time a word is identified, and there are many circumstances in which it is plausible to assume that the relevant changes do not take place. For example, when reading text, people tend to fixate on each specific word for only a brief moment, with an average fixation of approximately $200-250 \mathrm{msec}$ (Rayner \& Sereno, 1994). This may not be sufficient time to support the long-term modification of orthographic codes, particularly when multiple words are processed in quick succession. Indeed, in some models of word recognition, word codes are strengthened only if they are activated for a sufficient duration-activation for shorter durations would support masked priming but not long-term priming (Grossberg \& Stone, 1986). To the extent that lexical-orthographic codes are strengthened only under conditions in which sufficient attention is directed at the perceptual level, Tenpenny's (1995) argument loses force (for a similar analysis, see Carr \& Brown, 1990).

Finally, the role that lexical competition plays in mediating priming is theory dependent, and there is no reason to rule out all abstractionist approaches even if some specific instantiations of competition might eliminate longterm priming. It is worth noting that the lexical competition often postulated between words in abstractionist models is the product of active codes temporarily inhibiting their neighbors. So, for example, activation of the word table might temporarily lead to the inhibition of the word cable. But, if long-term priming reflects structural changes in the perceptual system involved in identifying words, the temporary inhibition from an active neighbor is irrelevant. Instead, the only relevant form of competition would be the product of structural changes to the system, perhaps changes in the interconnections between lexical entries. Whether changes of this sort occur, and whether it would eliminate long-term priming, remains unclear.

In sum, the longevity of long-term priming is not incompatible with abstractionist theories. On this approach, long-term priming reflects structural changes in 
the orthographic system that affect the later processing of the repeated items, with larger improvements associated with lower frequency words (see, e.g., Bowers, 1999b). Short-term priming, on the other hand, reflects the temporary activation (or opening) of abstract word codes, with short-term consequences. It is interesting to note that short-term masked priming, unlike long-term priming, is frequency insensitive (e.g., Bodner \& Masson, 1997; Forster \& Davis, 1984; Rajaram \& Neely, 1992), with equal benefits accruing to low- and high-frequency words. These contrasting results suggest that there are different underlying mechanisms that support short- and longterm priming, as suggested here. By contrast, Tenpenny (1995) argued that short- and long-term priming reflect the same underlying processes, and that short-term priming is short lived simply because weaker episodic traces support these effects. One question that needs to be addressed is why these weaker episodic memories are frequency insensitive, and stronger episodic traces are frequency sensitive.

\section{The Influence of Various Contextual Variables on Priming}

A common strategy for contrasting abstractionist and episodic theories has been to assess whether priming is affected by various study-to-test changes in the perceptual formats of items, or in the episodic context in which items are presented at study and test. To the extent that priming is sensitive to these manipulations, the results are thought to support episodic theories of priming and perception. These two forms of study-to-test changes are discussed in turn.

Surface form. Numerous studies have assessed the effects of study-to-test changes in the perceptual format of words on long-term priming, such as changing the letter case (e.g., READ-read) or font (e.g., read-read) of items. The standard argument is that abstractionist theories predict no effect of these manipulations, whereas episodic theories expect reduced priming following these changes-reductions that will be labeled specificity effects henceforth. As noted by Tenpenny (1995), the pattern of results reported in the literature is quite complicated, with a mixed set of results obtained across a large set of conditions. But, given that large specificity effects have been observed in some studies, and that a trend has been found in most experiments, Tenpenny concluded that these results support an episodic interpretation.

However, a number of issues need to be carefully considered in the drawing of conclusions from these results. First, recognition and recall are affected by study-test perceptual manipulations (see, e.g., Kirsner, 1973; Marsolek, Squire, Kosslyn, \& Lulenski, 1994), and performance on priming tasks is rarely process pure (Jacoby, 1991). Thus, it is important to consider the possibility that any specificity effects obtained on a priming task reflect explicit memory contamination. In this regard, it is worth noting that many of the larger specificity effects were reported in priming tasks involving rereading text or collections of words (e.g., Kolers \& Ostry, 1974). Such studies are particularly susceptible to explicit influences, given that participants often have many episodic cues and sufficient time to employ their explicit memories. Thus, to minimize this concern, only studies that assessed priming for single words will be considered for present purposes.

In addition, there are reasons to question the relevance of studies that have assessed priming for words presented in unusual formats, such as upside down or mirror reversed (e.g., Kolers \& Ostry, 1974; Masson, 1986). When words are presented in these unusual formats, participants take more time to respond, again raising the possibility that explicit memory strategies may intrude on performance. Furthermore, to the extent that these words are not processed in the normal fashion, they may not gain full access to the abstract lexical-orthographic codes that are presumed to mediate priming in abstractionist theories. Accordingly, failures to obtain abstract priming under these conditions do not provide a strong test for the abstractionist approach. For these reasons, the most relevant studies are those in which single study and test words are presented in familiar formats, but when the items are nevertheless visually dissimilar.

Studies satisfying these constraints are those that manipulate the letter case or font of the study and test words. When these studies are considered, the vast majority have failed to obtain significant specificity effects, although in most studies there is a small trend in that direction (for review, see Roediger \& McDermott, 1993; Tenpenny, 1995). Nevertheless, a number of these studies provide strong support for the abstractionist approach. Perhaps the strongest evidence comes from studies reporting robust priming between study-test items that are arbitrarily related in their perceptual form, but for which the priming is nevertheless modality specific. For example, using the perceptual identification task, Bowers (1996) assessed priming for words that are composed of letters that are visually dissimilar $(A / a, B / b, D / d, E / e, G / g$, $L / l$, and $Q / q$ ) in upper- and lowercase (e.g., DREADdread). Similar priming was obtained for study-test items presented in the same case $(17 \%$ improvement over baseline) and different case ( $16 \%$ improvement), and at the same time, little priming was obtained when words were spoken at study ( $5 \%$ improvement). More striking, in two studies using the lexical decision task, similar priming was obtained for Japanese words studied and tested in the same script (Kanji-Kanji or Hiragana-Hiragana) or different script (Kanji-Hiragana or Hiragana-Kanji) despite the fact that the scripts are completely unrelated in visual format (Bowers \& Michita, 1998). Averaging across the two studies, same-script priming was $28 \mathrm{msec}$ and cross-script priming was $24 \mathrm{msec}$, a difference that did not approach significance. Once again, little priming was obtained when items were spoken at study (6 msec averaging across studies), suggesting that cross-script priming was mediated by abstract orthographic codes. Lending fur- 
ther support to this conclusion, abstract word priming effects have been obtained between visually unrelated Hindi and Urdu scripts (Brown, Sharma, \& Kirsner, 1984) and between Cyrillic and Roman scripts (Feldman \& Moskovljevic, 1987). It should be noted, however, that the latter studies did not compare abstract visual priming with crossmodal priming, and thus it is possible that the effects were mediated by phonological or semantic representations.

The latter results are difficult to accommodate within an episodic account of priming. According to these theories, specific perceptual traces of words are laid down at study and test, and priming is obtained to the extent that the same perceptual processes are engaged at study and test (e.g., Roediger, 1990). However, it is difficult to see how these theories can account for the robust priming obtained between study-test items that are arbitrarily related in their visual form. Instead, these findings suggest that abstract orthographic codes map together visually dissimilar words, and that it is these abstract codes that support priming. (See Bowers \& Michita, 1998, and Polk \& Farah, 1997, for accounts of how such abstract orthographic knowledge may be acquired.)

Still, there has been a consistent trend for specificity effects across studies, and if a simple sign test were to be carried out on all of these studies, the effect would be significant. Although an advocate of the episodic approach might focus on this trend and argue that it poses problems for an abstractionist view, there are at least two reasons to argue otherwise. First, even though this trend has been obtained in studies that assessed priming for single words displayed in normal formats, the specificity effects may nevertheless be the product of explicit contamination. There is evidence that explicit memory can affect priming in these conditions (see, e.g., Bowers \& Schacter, 1990; Jacoby, 1991), and some studies have provided evidence that specificity effects are indeed the product of explicit contamination (Curran, Schacter, \& Bessenoff, 1996; Schacter, 1994).

However, there is a second and more interesting way to reconcile these small specificity effects with abstractionist theories, based on a series of studies that was not mentioned in Tenpenny's (1995) review. These studies provide evidence for the existence of separate abstract and specific visual perceptual codes for words, perhaps located in the left and right hemispheres, respectively. If this is the case, both abstractionist and episodic accounts of word perception may be correct, with abstract and specific representations differentially supporting priming under varying conditions.

One form of evidence in support of this conclusion comes from a series of long-term priming studies carried out by Marsolek and colleagues (Marsolek, 1995; Marsolek, Kosslyn, \& Squire, 1992; Marsolek et al., 1994), in which test words were directly presented to the participants' left visual fields (right hemisphere) or right visual fields (left hemisphere). The authors reported that priming is largely insensitive to study-to-test changes in letter case when items are flashed to the right visual field, but priming is sensitive to changes when items are flashed to the left. In fact, the specificity effects tended to mirror the task demands, with larger specificity effects obtained when the task requires specific perceptual attributes of items to be encoded (Burgund \& Marsolek, 1997). A similar pattern of abstract and specific priming was also observed for objects flashed to the participants' right and left visual fields, respectively (Marsolek, 1999). Furthermore, parallel results have been obtained in the auditory domain. For example, Schacter, McGlynn, Milberg, and Church (1993) reported a patient with a large left-hemisphere lesion that led to pure word deafness; he was able to repeat spoken words, but was unable to understand the meaning of these words. The patient showed robust priming for words repeated in the same voice ( $29 \%$ improvement over baseline) but minimal priming for words repeated in a different voice (4\% improvement). One interpretation of this finding is that the patient's intact right hemisphere mediated his ability to repeat words and supported same-voice priming, but damage to abstract phonological codes in the left hemisphere (that normally serve as access codes to semantics) prevented him from understanding the meaning of spoken words and reduced priming following the study-test voice change. Consistent with this hypothesis, control subjects showed much more abstract priming (23\% same voice vs. $16 \%$ different voice), suggesting that the left hemisphere is indeed important for supporting priming following voice changes (see Church \& Schacter, 1994, for additional evidence in support of this view).

It should be noted that the postulation of lateralized abstract and specific perceptual systems is also compatible with a variety of nonpriming results. For example, in the visual modality, perceptual systems in the left and right hemispheres play important roles in word and face identification, respectively. Given that reading typically requires recognizing text without regard to any specific perceptual information (e.g., font), and given that face recognition typically requires the identification of specific perceptual information to distinguish one face from another, these results may reflect abstract/specific hemispheric asymmetries (see, e.g., Farah, Wilson, Drain, \& Tanaka, 1998). Similarly, in the auditory modality, a number of studies indicate that patients with righthemisphere lesions show deficits in voice recognition (e.g., Van Lancker \& Kreiman, 1987) and in processing prosodic aspects of speech (e.g., Coslett, Roeltgen, Rothi, \& Heilman, 1987), whereas word identification disorders such as pure word deafness result from lefthemisphere lesions (e.g., Schacter et al., 1993). Along the same lines, dichotic listening studies with non-braindamaged individuals have found a left-ear advantage for processing aspects of voice information, whereas there is a right-ear advantage for identifying words (irrespective of voice; e.g., Kimura, 1973). Further converging evidence has been reported using brain imaging technologies. Using PET, Zatorre, Evans, Meyer, and Gjedde (1992) reported that the left hemisphere is more active than the 
right when participants identified phonemes in spoken syllables (conditions in which surface details of the words were irrelevant), and the right hemisphere was more active than the left when participants made pitch discriminations to the same items (conditions in which surface details were critical).

The above pattern of results may reflect a more basic functional constraint for perceptual systems. The visual system is confronted with two separate problems: It must recognize that different items (1) belong to the same abstract category when they are functionally equivalent (e.g., the visual patterns TABLE-table when one is reading text) yet also (2) belong to different specific categories when items are functionally distinct (e.g., TABLE-table must be distinguished if the task is to categorize upper- and lowercase words). Many contemporary theories ignore these two different requirements, and instead focus on accomplishing only one of these goals. For example, Biederman's (1987) GEON theory attempts to account for basic object recognition using abstract shape categories, but this theory cannot explain how different exemplars within a category (e.g., specific faces) are identified. By contrast, theories of face identification often rely on accessing highly specific perceptual memories, but have difficulty accounting for various abstractions (such as categorizing objects at a basic level; for discussion of this contrast, see Hummel \& Stankiewicz, 1998; Tarr \& Bülthoff, 1998). This has led some to argue that these functions are incompatible, thus requiring different systems (e.g., Farah et al., 1998; Marsolek \& Burgund, 1997; for a related argument, see Goodale, Milner, Jakobson, \& Carey, 1991; but see Hummel \& Stankiewicz, 1998).

If two different perceptual systems are involved in identifying information, one abstract and one specific, it is highly likely that both systems contribute to priming. On this view, then, small specificity effects do not contradict the claim that abstract orthographic knowledge supports both reading and priming phenomena. Instead, these findings only indicate that abstract lexical-orthographic knowledge does not support all priming phenomena.

Before this discussion is concluded, it is important to note that similar issues have also been addressed in the masked priming domain. Although Tenpenny (1995) claimed that this issue had not been explored, a number of authors found no correlation between the size of priming and the visual similarity of the primes and targets (e.g., Evett \& Humphreys, 1981; Humphreys, Besner, \& Quinlan, 1988; for a related finding, see Davis \& Forster, 1994). More recently, Bowers et al. (1998) contrasted masked priming for upper- and lowercase visually similar words (e.g., kiss-KISS) and visually dissimilar words (e.g., edge-EDGE). No effect of this manipulation (not even a trend) was found in a lexical decision or a verbnoun categorization task, and only a small effect arose in a perceptual identification task in which the targets were degraded. Furthermore, a phonological basis for this crosscase priming was ruled out, given that little priming was obtained between homophones in the lexical decision task. Perhaps more striking, robust cross-case masked priming between visually dissimilar prime-target pairs was observed in a letter-by-letter surface alexic patient (I.H.) who could not gain fast access to phonological or semantic knowledge (Bowers, Arguin, \& Bub, 1996). Indeed, robust priming was obtained in I.H. when primes were presented in case-alternated format (e.g., $r E a D$ $R E A D$; Arguin, Bub, \& Bowers, 1998), as has been observed with individuals with normal reading skills (Forster \& Guess, 1996). Given the nature of I.H.'s reading deficit, it is unlikely that this cross-case priming was mediated by phonological or semantic representations.

To summarize, robust long-term priming has been obtained between visually dissimilar (sometimes unrelated) study-test words, and at the same time, these effects are largely modality specific. These findings are predicted on abstractionist theories and cannot easily be accommodated within an episodic framework where the basis for priming is the perceptual overlap between study and test items. Similar results have been obtained in the masked priming paradigm, where equivalent priming is generally obtained between prime-target pairs that are visually similar and dissimilar. Finally, to the extent that there is a consistent trend to observe small specificity effects in long-term priming, these results may be attributed to either explicit memory contamination or priming within a separate perceptually specific system, perhaps located within the right hemisphere.

Episodic context. The other common strategy for assessing the influence of specific information on priming is to manipulate the episodic context in which repeated items are presented at study and test (e.g., presenting repeated target words with different cue words at study and test). To the extent that priming is affected by context manipulations, the results are thought to support episodic theories of priming and word identification. This literature is largely restricted to long-term priming studies, and as reviewed by Tenpenny (1995), the findings are quite complex and often mixed. Nevertheless, she concludes that the results lend more support to episodic theories. But again, this conclusion is unwarranted by the data.

As was the case with the specificity results described above, there is a problem that recall and recognition are sensitive to changes in episodic context, and long-term priming tasks are rarely process pure. Thus, once again, it is important to consider the possibility that any episodic effects obtained in a priming task reflect explicit memory contamination. To minimize this concern, only those studies that assessed priming for target words presented in isolation or in the context of a single cue word at test will be described. For review of studies that assessed priming for test words presented in the context of paragraphs, sentences, or word triplets, see Tenpenny (1995).

One of the first demonstrations that single-word priming can be affected by context was reported by Jacoby (1983a), who observed greater priming in a perceptual 
identification task when a high $(90 \%)$ as opposed to a low $(10 \%)$ proportion of the study items were later repeated at test. Allen and Jacoby (1990) replicated this pattern of results using the same task, but included a manipulation intended to assess whether the increased priming in the high-overlap condition was the product of participants "catching on" and using explicit memory to enhance their performance. Specifically, two study conditions were included. In one, the participants simply read words at study, and in a second, words were presented in an anagram format in which participants were required to generate the solution. On the basis of past research, it was expected that priming would be reduced for the generated words, whereas recognition would be better (Jacoby, 1983b). They further argued that if context effects in priming were the product of explicit memory contamination, the context effects should be larger for items studied in the anagram format, because these items should be best remembered and thus most subject to explicit memory strategies. However, they failed to observe greater context effects for the generated words in the two priming experiments and in fact observed a trend for larger context effects for the read words in both cases. On the basis of these findings, the authors concluded that performance was not contaminated by explicit memory, thus supporting an episodic account of priming in which context affects priming.

However, there are a number of problems with this conclusion. First, in Experiment 1 of Allen and Jacoby (1990), recognition memory was actually more sensitive to the proportional context manipulation when items were read than when they were generated, and there was no significant difference in Experiment 2 (although there was a trend for larger effects in the generate condition). Accordingly, the observed tendency to obtain larger context effects for priming in the read condition in the two studies does not provide strong evidence for a dissociation between priming and recognition memory. Second, these results were not replicated by Challis and Roediger (1993) when they assessed priming in a fragment completion task. Indeed, they observed a nonsignificant trend for more priming in the low- as opposed to the high-proportion overlap condition. They also cited the unpublished dissertation of Donnelly (1988), who failed to observe an effect of proportion overlap in the fragment completion task. Third, Challis and Roediger noted a number of confounds in the Jacoby (1983a) and Allen and Jacoby studies that raise problems for interpretation, including the fact that participants in the $90 \%$ condition were informed about the relationship between study and test, whereas this was not the case in the $10 \%$ condition, as well as the fact that the manipulation of proportion overlap was correlated with test order in Allen and Jacoby's second experiment. Thus, there is no compelling evidence that proportion overlap affects priming independently of explicit memory contamination. Related studies have manipulated episodic context by changing the room, the computer, or the experimenter at study and test, and null effects have typically been obtained (e.g., Jacoby, 1983a; Jacoby \& Witherspoon, 1982).

Another way to manipulate episodic context is to change the manner in which words are encoded at study and test. To the extent that priming is sensitive to the specific encoding operations engaged at study and test, the results might appear to support episodic accounts. A striking example of such an effect was reported by Vriezen, Moscovitch, and Bellos (1995), who asked participants to make semantic categorizations to written words at study and test. The critical finding was that priming was eliminated when participants performed different categorizations, even though the same perceptual encoding was required at study and test (e.g., in one condition, participants categorized the referents of words in terms of their size at study, and as natural vs. man-made at test). This finding suggests that semantic context affects (even eliminates) perceptual priming. A problem with this study, however, was that the authors included relatively high-frequency words, ranging from 4 to 521 per million, with a mean of 80.5 (Francis \& Kučera, 1982), and priming tends to be reduced for high- relative to low-frequency words (e.g., Bowers, 1999b; Forster \& Davis, 1984; Rajaram \& Roediger, 1993). When Bowers (1999a) replicated this study with low-frequency words, robust priming was obtained.' Gerard and Scarborough (1989) also obtained evidence that semantic context is not critical for singleword priming. They asked Spanish-English bilingual speakers to perform lexical decisions in their different languages at study and test, and compared priming between cognates with the same spellings and pseudocognate homographs (Spanish-English words that share the same spelling but have different meanings). They reported equivalent priming for these items, showing that repeated access to orthographic codes is critical for priming, whereas repeated encoding of the same semantic context is not. Consistent with this story, priming is greatly reduced or eliminated between Arabic and French cognates that are orthographically unrelated due to their different scripts (Bowers, Mimouni, \& Arguin, 1999).

The most common way to manipulate episodic context, however, has been to embed words in different written contexts at study and test. Although many of these studies are taken to support episodic over abstractionist approaches, a close review of the data does not support this conclusion. For example, Oliphant (1983) failed to obtain priming when participants studied target words embedded in text and were later tested with the same words in isolation, leading him to support an episodic account. However, as noted earlier, there is no guarantee that words presented in the context of sentences are perceptually processed to the same extent as when they are presented in isolation. Accordingly, a reduction in priming is not surprising from an abstractionist position that attributes priming to the strengthening of abstract orthographic codes. Furthermore, as in Vriezen et al.'s (1995) study, Oliphant assessed priming for high-frequency words. When MacLeod (1989) replicated Oliphant's 
study using lower frequency words, significant priming was obtained.

A more common way to manipulate the written context, however, has been to contrast priming when target words were repeated along with the same cue word at study and test (e.g., study the cue-target pair windowreason and test with the cue-target pair window-reason), compared with a condition in which different cue words served as context at study and test (e.g., study the cuetarget pair table-reason and test with the pair windowreason). If priming is enhanced for targets repeated in the same compared with the different context-associative priming - then the results would appear to support an episodic account.

Graf and Schacter $(1985,1987,1989$; Schacter \& Graf, 1986,1989 ) reported robust associative priming in the stem completion task as well as observing various dissociations between priming and recognition performance. However, they did not obtain associative priming in densely amnesic patients (Schacter \& Graf, 1986), and Bowers and Schacter (1990) obtained associative priming only when participants were aware that items repeated at study and test. Furthermore, associative priming was obtained only when items were elaboratively encoded at study (Graf \& Schacter, 1985; Schacter \& Graf, 1986; but see Micco \& Masson, 1991), conditions that support good explicit memory. The restricted conditions in which this priming is obtained raise the possibility that these effects are largely the product of explicit contamination. Indeed, Reingold and Goshen-Gottstein (1996a, 1996b) assessed stem completion priming using the process dissociation paradigm (Jacoby, 1991) and found that the associative effects were often the product of intentional memory (although they were able to obtain a small context effect that was attributable to automatic processes when participants copied the word pairs at study).

Associative effects were also found in a speeded naming task (Moscovitch, Winocur, \& McLachlan, 1986). However, Musen and Squire (1993) had difficulty replicating these results for both amnesic patients and normal participants unless multiple study trials were included. Using the lexical decision task, McKoon and Ratcliff (1979) found association-specific repetition effects, but attempts to replicate this finding have been largely unsuccessful (e.g., Carroll \& Kirsner, 1982; Neely \& Durgunoğlu, 1985; Smith, MacLeod, Bain, \& Hoppe, 1989). One possible reason for the discrepant findings is that McKoon and Ratcliff (1979) used long (650-800 msec) stimulus onset asynchronies between items that formed pairs, whereas other investigators did not. Thus once again, the associative effects may have been the product of explicit memory contamination.

The strongest evidence for associative effects in priming was reported in a series of studies by Goshen-Gottstein and Moscovitch (1995a, 1995b). The authors used a simultaneous lexical decision task in which participants were asked to indicate whether two simultaneously pre- sented letter strings were both legal English words. Decisions were faster when words were repeated in the same relative to different pairings at study and test, and further, the effects dissociated from recognition memory. Indeed, the authors reported that the associative effect was not diminished following shallow relative to elaborative encoding conditions, suggesting that the context effects could not be attributed to explicit contamination.

Although the latter findings appear to indicate that priming can be sensitive to episodic contexts, independently of explicit contamination, a finding by Marsolek, Schacter, and Nicholas (1996) suggests a different way of interpreting these findings that is consistent with an abstractionist framework. The authors assessed associative priming in a stem completion task when test items were presented to the left and right visual fields of participants, and obtained associative effects only for items presented in the left visual field (right hemisphere). Furthermore, the associative effects in the right hemisphere were eliminated when word pairs were presented in different cases at study and test. This combination of findings suggests that these associative effects were mediated by a perceptually specific system located in the right hemisphere, and that orthographic representations in the left hemisphere (which would normally mediate word identification, see, e.g., Peterson, Fox, Posner, Mintun, \& Raichle, 1989) were insensitive to this contextual manipulation, consistent with abstractionist views. On this view, the associative effects reported by Goshen-Gottstein and Moscovitch (1995a, 1995b) also reflect the contribution of a specific system in the right hemisphere. Consistent with this proposal, both study and test items in these studies were presented in uppercase letters (Goshen-Gottstein, personal communication, February 10, 1999), and further, the authors obtained the same amount of associative priming for low- and high-frequency words. This contrasts with within- and cross-case priming for single words, which is highly sensitive to frequency manipulations (e.g., Bowers, 1999b; Forster \& Davis, 1984).

To summarize, only a few studies have reported associative effects under conditions in which explicit contamination cannot be ruled out, and in these cases, it is possible that the effects were mediated by a specific perceptual system, perhaps within the right hemisphere. The orthographic representations within the left hemisphere, by contrast, appear to be insensitive to these context manipulations. Similarly, many of the studies that assessed episodic context effects for test words presented in isolation also may have been affected by explicit memory. Under conditions in which these influences are minimized, the priming results are most compatible with abstractionist approaches.

Before concluding, I should note that there is one recent demonstration that context can also affect shortterm priming. Bodner and Masson (1998) found that masked priming was enhanced when a high rather than a low proportion of the prime-target pairs were the same, 
particularly for low-frequency words. Unlike the Jacoby (1983a) and Allen and Jacoby (1990) studies, these results cannot be the product of explicit contamination, because the primes were presented for $60 \mathrm{msec}$ and masked, making the primes unavailable to consciousness. On the basis of these results, the authors supported an episodic account of short-term priming. It will be important to pursue this finding further to determine the extent to which such a finding is problematic for abstractionist theories.

Word-pseudoword differences. The finding that long-term priming extends to various novel materials, including pseudowords (see, e.g., Feustel, Shiffrin, \& Salasoo, 1983; see Bowers \& Schacter, 1993, for a review of pseudoword priming results obtained with amnesic patients) has often been considered incompatible with abstractionist accounts that attribute priming to preexisting abstract word codes. However, as noted by Dorfman (1994), most studies have assessed priming for pseudowords that are very similar to familiar words, and accordingly, any priming for these items might in principle be mediated by the preexisting sublexical representations these items share with real words (or alternatively, this priming could be supported by a number of orthographically related words). Accordingly, the mere fact that priming extends to pseudowords cannot be used to contradict abstractionist theories.

Tenpenny (1995) agreed with this analysis, but challenged another argument that has been put forward in support of abstractionist theories. That is, there are now various reports that word and pseudoword long-term priming differ in a number of ways, which has led some to argue for the existence of abstract lexical-orthographic codes (e.g., Salasoo \& Shiffrin, 1985; Whitlow, 1990). The general argument here is that these differences reflect the contribution of preexisting orthographic representations to which only words have full access. However, Tenpenny. argued that that these differences can also be explained within an episodic framework, because the differences may simply reflect the fact that episodic memory codes for words already exist, which is not the case for pseudowords. Indeed, explanations for some of the word-pseudoword differences have been proposed without positing abstract orthographic codes (Logan, 1990; Rueckl \& Olds, 1993). Accordingly, Tenpenny concluded that word-pseudoword differences do not strongly favor one approach over another.

However, one long-term word-pseudoword difference reported subsequent to Tenpenny's (1995) review is more easily interpretable within the abstractionist framework. That is, whereas priming for words is largely insensitive to study-to-test case changes, priming for pseudowords is reduced by approximately $50 \%$ when the items are visually dissimilar (e.g., NEGA-nega; Bowers, 1996). One possible interpretation of this finding is that only words have complete access to the abstract lexicalorthographic codes, and thus only words show abstract visual priming (for related findings, see Whittlesea \& Brooks; 1988; Whittlesea \& Cantwell, 1987). On this view, the specific effects for pseudowords reflect the separate contribution from a specific perceptual system, perhaps located in the right hemisphere. Note, the pseudoword priming results parallel Marsolek et al.'s (1996) finding that associative priming is eliminated when items are presented in a different case at study and test.

The suggestion that word and pseudoword priming are mediated by different systems may provide a way to reconcile abstractionist theories with the finding that priming also extends to random letter strings (e.g., Bowers, 1994; Hamann \& Squire, 1997). At first, the latter findings appear to be particularly problematic for abstractionist theories, given that sublexical representations cannot support these effects (the claim that single-letter codes might support priming for these items is difficult to maintain given that little or no priming is obtained between form-related words, such as car-card; e.g., Napps $\&$ Fowler, 1987). However, on the present argument, priming for random letter strings may also be mediated by a specific perceptual system within the right hemisphere. A prediction of this view, then, is that priming for these items should also be case specific. Thus far, this prediction is untested.

With regard to short-term priming, Forster and colleagues have reported a striking contrast between word and pseudoword priming when participants make lexical decisions to targets. Whereas word priming is robust and insensitive to frequency, pseudoword priming is generally absent (see, e.g., Forster \& Davis, 1984, 1991; Forster et al., 1987; for review, see Forster, 1998). On the basis of these null pseudoword results, Forster and colleagues argued that short-term priming for words is mediated by abstract lexical codes. However, as argued by Humphreys et al. (1990), among others, the absence of pseudoword priming in these studies may reflect an idiosyncratic property of the lexical decision task. That is, the pseudoword primes may improve the perceptual processing of the repeated targets (as is the case for words), but this improved perceptual processing may bias participants to respond "word" to the pseudowords, given that words tend to be more easily processed than pseudowords. This bias may counteract the improved perceptual processing of the pseudowords, resulting in no priming. Indeed, in an identification task that does not include the bias associated with the lexical decision task, Humphreys et al. (1990) obtained priming for pseudowords, and Bodner and Masson (1997) observed pseudoword priming in the lexical decision task under conditions designed to reduce this bias. On the basis of their findings, Bodner and Masson (1997) defended an episodic account of short-term priming (see Forster, 1998, for a different interpretation of these findings).

For present purposes, what is important to note is that the presence of short-term priming for pseudowords in some tasks does not by itself support episodic theories of 
short-term priming. As is the case with long-term priming, these effects may be mediated by abstract sublexical codes, as argued by Humphreys et al. (1990), for example. As noted earlier, one property of short-term word priming is that it is insensitive to the visual changes between prime and targets, with equal priming obtained between prime and targets that are visually similar (e.g., kiss$K I S S$ ) and dissimilar (e.g., read-READ) (Bowers et al., 1998). Thus, on an abstractionist account, short-term pseudoword priming should also be unaffected by these perceptual variables (unless items are specifically presented to the right hemisphere). On an episodic account, such changes should impact on priming. The verdict is still out.

Morphological priming. Tenpenny (1995) claimed that the strongest evidence in support of an abstractionist approach comes from studies that have assessed longterm priming between morphologically related words. The typical finding is that equivalent priming is obtained between inflectionally related (e.g., cars-car) and repeated words (e.g., car-car), and given that little or no priming is obtained between orthographic neighbors (e.g., card-car; see, e.g., Napps \& Fowler, 1987; Stolz \& Feldman, 1994), this priming cannot be attributed to the visual or phonological overlap between items. Further, this priming cannot be attributed to semantic representations because semantic priming does not persist for more than a few seconds under conditions that support long-term morphological priming (see, e.g., Henderson, Wallis, \& Knight, 1984).

Similar findings have been obtained in short-term priming paradigms. For example, Grainger et al. (1991) obtained robust priming between morphologically related items, and these effects could not be attributed to orthographic or phonological knowledge given that inhibitory priming was obtained between nonmorphologically related items matched in terms of their orthographic and phonological overlap (see also Forster et al., 1987). Furthermore, because little priming is obtained between semantically related items in the masked priming paradigm (see, e.g., de Groot \& Nas, 1991), it is difficult to attribute these effects to semantic factors. In addition, in a related short-term priming task, Stolz and Besner (1998) were able to dissociate semantic and morphological priming following a letter search task on the prime: Semantic priming was eliminated under conditions in which participants searched primes for a specific letter, whereas robust morphological priming was obtained under the same conditions. Similarly, Laudanna, Badecker, and Caramazza (1989) obtained short-term (nonmasked) morphological priming between Italian words (e.g., posto [door]-posti [doors], which share the stem post-), whereas inhibitory priming was obtained between nonmorphologically related words that share homophonic stems (portare [to carry]-porte [doors], which share the homographic stem port-), indicating that phonological overlap between items is not responsible for the morphological priming. On the basis of these findings, these authors concluded that morphological relations are coded separately from semantic and phonological codes.

These priming results are compatible with models that explicitly encode morphological relations within the orthographic system (Caramazza, Laudanna, \& Romani, 1988; Taft \& Forster, 1975), but are difficult to accommodate within an episodic framework, in which priming reflects the perceptual overlap between items. In defense of the episodic view, Tenpenny (1995) noted that some studies observed more priming between repeated items relative to morphologically related items, indicating that the specific perpetual features can play a role in morphological priming. Further, she suggested, in accordance with Rueckl and Dror (1994), that morphological priming may reflect some sort of association between perceptual and semantic factors, although the precise nature of this association is left unspecified, and the way such associations can account for many of the results described above remains unclear. At present, these results fit more naturally within an abstractionist framework, as Tenpenny herself conceded.

\section{SUMMARY OF REPETITION PRIMING RESULTS}

In sum, none of the priming results reviewed by Tenpenny (1995) are incompatible with abstractionist theories of word priming and word identification, and some of the priming results described above are difficult to accommodate within a purely episodic framework. Particularly problematic are the findings that robust short- and long-term priming is obtained between visually dissimilar prime-target pairs under conditions in which semantic and phonological processes can be ruled out. Tenpenny argued that episodic word identification models analogous to Medin and Schaffer's (1978) context model of categorization could account for the various abstract crosscase priming effects. However, since priming in this sort of model is a function of the perceptual similarity of the study and test items, it is difficult to see how this approach can accommodate the priming obtained between visually unrelated words (e.g., READ-read). Still, in order to account for all of the data reviewed above, it may be necessary to postulate two different perceptual systems that support priming, one that represents words in an abstract format, and another that encodes the perceptual details of inputs. Interestingly, the hypothesis that separate abstract and specific perceptual codes exist is also supported by various nonpriming results (e.g., Farah et al., 1998).

\section{Additional Sources of Evidence in Support of the Abstractionist Position}

Although Tenpenny's (1995) review focused on repetition priming studies, her conclusion was not restricted to theories of priming. Rather, she made the more general 
claim that word identification is mediated by episodic representations, questioning the existence of abstract orthographic codes altogether. This might be a reasonable approach if the only findings relevant to this question were those priming results reviewed by Tenpenny. However, there are numerous other experimental findings relevant to this question, many of which strongly support the existence of abstract orthographic knowledge. In this section, I briefly describe some of these additional findings that need to be considered when one is contrasting episodic and abstractionist theories of word identification.

One of the more striking forms of evidence in support of abstract orthographic representations was reported by Coltheart (1981). He described a conduction aphasic patient who could not name individual letters or name pseudowords (e.g., nega), but who nevertheless was able to match upper- and lowercase pseudowords that were perceptually dissimilar (e.g., NEGA-nega) without difficulty. Given that these items are (1) meaningless, (2) perceptually dissimilar in upper- and lowercase, and (3) unpronounceable by the patient, Coltheart (1981) concluded that the patient must have accessed abstract orthographic codes in order to perform the task. A similar result was obtained with a person with a developmental reading disability (Rynard \& Besner, 1987). The patient was able to name only $69 \%$ and sound out $65 \%$ of letters, but nevertheless was $100 \%$ accurate in performing cross-case letter matching. The letters he was unable to name or sound out included the letters $E, G$, and $R$, which are visually dissimilar in upper- and lowercase.

In addition, McClelland (1976) reported that the word superiority effect (WSE) is equally large for words presented in case-uniform and mixed-case conditions; for example, the words $F A D E$ and $f A d E$ were both better identified than the matched pseudowords $G A D E$ and gAdE in a task in which participants were asked to identify the complete items. Given that both mixed-case words and pseudowords have unfamiliar visual patterns, McClelland concluded that the WSE was mediated by abstract lexical-orthographic representations. Bowers, Bub, and Arguin (1996) reported the same finding in a letter-by-letter surface alexic patient who had slow access to phonological and semantic knowledge, suggesting that the abstract effects were not the product of phonological or semantic representations.

Further evidence for abstract word codes was reported by Besner, Coltheart, and Davelaar (1984) using a matching task. Participants were required to respond "same" for pseudowords that were physically identical (e.g., $h I L e-h I L e)$, and "different" otherwise. The critical finding was that participants took longer to reject items that shared the same abstract letter codes (e.g., hILe-HilE) than orthographically different but phonologically identical items (e.g., hILE-HyLE), suggesting that abstract letter codes are automatically computed, which hinder the "different" response.
Rayner, McConkie, and Zola (1980) used eye-tracking technology to determine the types of information that are encoded from parafoveally presented words. While participants focused on a cross, a word was presented away from fixation, and during a saccade to this item, the word was replaced by a second word that was (1) physically identical to the first word, (2) the same word but presented in a different case, (3) a different word that shared the same initial phoneme, (4) a semantically related word, or (5) a different word altogether. Latencies to name the parafoveal words on the next fixation were facilitated equally in conditions (1) and (2), and no facilitation was obtained in (3) and (4) compared with the baseline condition (5). On the basis of this pattern of results, the authors concluded that parafoveal preview facilitation was the product of the words contacting abstract orthographic codes (see also McConkie \& Zola, 1979).

Finally, Mozer (1989) reported a homogeneity effect in which participants underestimated the number of letters in a briefly presented display when the same letters were repeated. A homogeneity effect extended to displays that contained upper- and lowercase letters that were visually dissimilar. For example, participants more often failed to report two letter $e$ in the briefly flashed pattern peb CER, compared with when different letters were presented in the same position. The finding that the homogeneity effect extended to cross-case letters led Mozer to argue for the existence of abstract letter codes.

In sum, the studies reviewed in this section strongly support the conclusion that orthographic knowledge is coded in an abstract format in such a way that different exemplars of the same stimulus (e.g., $R E A D$-read) map onto common representations. Any purely episodic account of visual word identification needs to accommodate not only the various priming results, but also these findings.

\section{Embedding Priming Within an Abstractionist Theory of Word Identification}

On the basis of the above considerations, there are strong grounds to argue that abstract orthographic codes support word identification, and that repetition priming is mediated, in part, by these orthographic codes. In this final section, I briefly outline the sorts of abstractionist theories that may satisfy the above constraints.

First, however, it is important to note some problems with the classic abstractionist theory of Morton (1979) and the related countermodel of Ratcliff and McKoon (1997). Although there are a number of important differences between these theories, on both accounts, word identification involves activating abstract lexicalorthographic word codes above some threshold, and priming reflects the modification of orthographic knowledge in such a way that repeated words are more easily activated beyond threshold. They also share two additional features that are problematic. First, on both accounts, priming reflects a change in bias rather than an improvement in perceiving repeated items. That is, the 
modification of orthographic knowledge is not thought to improve the efficiency with which words are encoded, but rather, to result in a tendency to interpret test words as previously studied words. This improves performance when study and test words are the same (e.g., study word $=$ table, test word $=$ table) , and hinders performance otherwise (e.g., study word $=$ cable, test word = table), with benefits equaling costs. As both Morton and Ratcliff and McKoon explicitly noted, the amount of information available to lexical-orthographic word codes is independent of repetition effects (or frequency effects) and is solely determined by the properties of the stimuli (e.g., duration, contrast, signal-to-noise ratio, etc.).

This bias interpretation is problematic because recent evidence suggests that priming reflects, in part, a change in perceptual sensitivity so that the orthographic system is more efficient in processing repeated words. Specifically, Bowers (in press) reported that priming for low-frequency words reflects a change in sensitivity when items are repeated once, whereas priming for high-frequency words under the same conditions reflects a change in bias. Raaijmakers, Schooler, and Shiffrin (1997) reported evidence that priming for high-frequency words also reflects a change of sensitivity when items are repeated multiple times. In addition, using the same procedure, Masson and MacLeod (1996) reported a trend for priming in seven of eight studies they carried out with "common words" (the exact frequency was not specified) studied once, suggesting a change in $d^{\prime}$. These results suggest that priming is a manifestation of learning that improves the perceptual encoding of repeated items, with low-frequency words benefiting more than high-frequency words. ${ }^{2}$ This relation between word learning and priming is denied by the Morton (1979) and Ratcliff and McKoon (1997) models.

The claim that priming reflects pure bias is related to a second deficiency of these models; namely, they do not incorporate any mechanisms for learning, and are thus mute regarding how orthographic knowledge is acquired in the first place. As a consequence, these models must be hand-wired in order to identify words. Clearly, this is a limitation, because any complete theory must incorporate learning principles. Indeed, what may be needed is an abstractionist account of word identification that incorporates learning principles to support the acquisition of orthographic knowledge, and in which priming is a natural by-product of this learning process.

Unfortunately, many abstractionist models of word identification have not incorporated learning mechanisms (or any mechanism that could support long-term bias), and, needless to say, such models cannot account for longterm priming (e.g., Forster, 1985; McClelland \& Rumelhart, 1981; Paap, Newsome, McDonald, \& Schvaneveldt, 1982). However, connectionist or neural network models of single-word reading have incorporated learning principles (Grossberg, 1980; Grossberg \& Stone, 1986; Plaut, McClelland, Seidenberg, \& Patterson, 1996; Seidenberg
\& McClelland, 1989; also see Coltheart, Curtis, Atkins, \& Haller, 1993). Accordingly, a promising approach to understanding visual word priming phenomena may be to embed theories of priming within network models of word identification.

It should be noted that Tenpenny (1995) described network theories of priming as "weakly episodic," which she contrasted with the abstractionist approach I have been defending. According to Tenpenny, the crucial difference between the weakly abstractionist and the weakly episodic views is that the weakly abstractionist view posits fundamentally different forms of representations for episodes and lexical entries, whereas the weakly episodic view holds that episodes and lexical entries are represented together, with the abstractions being an emergent property of the overlaid episodic instances. Tenpenny argued that connectionist models are of the latter sort, which is a nonabstractionist position.

However, it is quite possible to develop connectionist models with separate sets of representations for abstract and specific information. For instance, connectionist models have been developed to represent abstract information, for the sake of both object identification (Hummel \& Biederman, 1992) and word identification (Polk \& Farah, 1997). Indeed, Polk and Farah developed a model that can learn abstract letter codes, even between arbitrarily related letters, such as $A / a$ (but see Bowers \& Michita, 1998, for findings that require a modification of their model). The critical point to note is that these connectionist models were designed to learn abstractions, and are unable to represent the specific perceptual details of inputs that are often used to support episodic memory.

On the basis of these considerations, Marsolek and colleagues have argued that separate networks are needed to represent information in abstract and perceptually specific formats, and they have described models that use back-propagation learning principles that categorize inputs at different levels of specificity (Marsolek \& Burgund, 1997). Another network approach that can separate specific and abstract information is the adaptive resonance theory (ART) of Grossberg and colleagues (e.g., Carpenter \& Grossberg, 1987; Grossberg, 1980; Grossberg \& Stone, 1986). On this theory, there is a so-called vigilance parameter that affects the grain size of the mappings that are learned. With low vigilance parameters, broad categories are learned; a wide range of perceptual inputs are categorized together, whereas with high vigilance parameters, visually similar inputs are categorized separately. It is possible that neural networks for pattern recognition in the left and right hemispheres are characterized by different vigilance parameters; one may operate in a more "abstract" mode, and the other in a more "instance" mode. Indeed, a version of ART, namely ARTMAP (Carpenter, Grossberg, \& Reynolds, 1991), provides a mechanism by which arbitrary mappings (e.g., 
A/a) can be learned. These ART models have been used to account for various visual and spoken word recognition results reported in the literature (Grossberg, Boardman, \& Cohen, 1997; Grossberg \& Stone, 1986), and hold promise for accounting for various priming phenomena as well.

The claim that long-term priming for words is best understood as a by-product of learning within the orthographic system suggests that this phenomenon can be used to constrain theories of word identification, much like short-term priming is typically used. Indeed, longterm priming may provide important insight into how orthographic (and other perceptual systems) learn--an issue that short-term priming phenomena cannot address if it reflects the temporary activation of preexisting orthographic codes, as argued here. To date, long-term priming has not been extensively used in this capacity, but on the present argument, it should. ${ }^{3}$

\section{Overall Summary}

Tenpenny (1995) argued that priming results reported in the literature are compatible with a purely episodic account of word identification and priming, and she questioned the need to posit abstract orthographic knowledge to accomplish these functions. However, contrary to this conclusion, various findings indicate that abstract orthographic knowledge exists, and that these codes contribute to both word identification and priming. Given evidence that highly specific perceptual information also contributes to word identification and priming, it appears that a "weakly abstractionist" position is the most justified on the current evidence, with separate abstract and specific visual codes contributing to priming and word identification. Arguably, abstract orthographic codes within the left hemisphere are largely responsible for word priming phenomena as well as visual word identification processes. Specific perceptual codes may only play a major role in these processes under unusual conditions, such as when words are flashed to the left visual field, or when the words are unfamiliar or presented in novel formats (e.g., upside down or mirror reversed).

\section{REFERENCES}

Allen, S. W., \& JaCoBY, L. J. (1990). Reinstating study context produces unconscious influences of memory. Memory \& Cognition, 18 270-278.

Arguin, M., Bub, D., \& Bowers, J. S. (1998). Extent and limits of covert lexical activation in letter-by-letter reading. Cognitive Neuropsychology, 15, 53-92.

Besner, D., Coltheart, M., \& Davelaar, E. (1984). Basic processes in reading: Computation of abstract letter identities. Canadian Journal of Psychology, 38, 126-134.

Biederman, I. (1987). Recognition-by-components: A theory of human image understanding. Psychological Review, 94, 115-147.

Biederman, 1., \& CoOper, E. E. (1991). Evidence for complete translation and reflectional invariance in visual object priming. Perception, 20, 585-593.

Blaxton, T. A. (1989). Investigating dissociations among memory measures: Support for a transfer-appropriate processing framework Journal of Experimental Psychology: Learning, Memory, \& Cognition, 15, 657-668.
BoDNER, G. E., \& MAsson, M. E. J. (1997). Masked repetition priming of words and nonwords: Evidence for a nonlexical basis for priming. Journal of Memory \& Language, 37, 268-293.

Bodner, G. E., \& MASSON, M. E. J. (1998). Repetition prime proportion modulates masked repetition priming. Abstracts of the Psychonomic Society, $\mathbf{3}, 15$

BowERS, J. S. (1994). Does implicit memory extend to legal and illegal nonwords? Journal of Experimental Psychology: Learning, Memory, \& Cognition, 20, 534-549.

BowERS, J. S. (1996). Different perceptual codes support word and pseudoword priming: Was Morton right all along? Journal af Experimental Psychology: Learning, Memory, \& Cognition, 22, 13361353.

Bowers, J. S. (1999a). Perceptual priming is obtained in a semantic classification task: Comment on E. Vriezen, M. Moscovitch, and S. A. Bellos (1995). Manuscript submitted for publication.

BowERS, J. S. (1999b). Priming is not all bias: Commentary on Ratcliff and McKoon (1997). Psychological Review, 106, 582-596.

BoWERS, J. S. (in press). The modality-specific and -nonspecific components of long-term priming are frequency sensitive. Memory $\&$ Cognition.

Bowers, J. S., Arguin, M., \& Bub, D. (1996). Fast and specific access to orthographic knowledge in a case of letter-by-letter surface alexia. Cognitive Neuropsychology, 13, 525-567.

Bowers, J. S., BuB, D., \& ARGUIN, M. (1996). A characterization of the word superiority effect in a case of letter-by-letter surface alexia. Cognitive Neuropsychology, 13, 415-441.

BowERS, J. S., \& MichITA, Y. (1998). An investigation into the structure and acquisition of orthographic knowledge: Evidence from cross-script Kanji-Hiragana priming. Psychonomic Bulletin $\&$ Review, 5, 259-264.

Bowers, J. S., Mimouni, Z., \& Arguin, M. (1999), Orthography plays a critical role in cognate priming: Evidence from French/ English and Arabic/French cognates. Manuscript submitted for publication.

Bowers, J. S., \& SCHACTER, D. L. (1990). Implicit memory and test awareness. Journal of Experimental Psychology: Learning, Memory, \& Cognition, 15, 763-778.

Bowers, J. S., \& SCHACTER, D. L. (1993). Priming of novel information in amnesic patients: Issues and data. In P. Graf \& M. E. J. Masson (Eds.), Implicit memory: New directions in cognition, development, and neuropsychology (pp. 303-326). Hillsdale, NJ: Erlbaum.

Bowers, J. S., Vigliocco, G., \& HAAN, R. (1998). Orthographic, phonological, and articulatory contributions to masked letter and word priming. Journal of Experimental Psychology: Human Perception \& Performance, 24, 1705-1719.

Brown, H. L., Sharma, N. K., \& KirSner, K. (1984). The role of script and phonology in lexical representation. Quarterly Journal of Experimental Psychology, 36A, 491-505.

Burgund, E. D., \& MARSOLEK, C. J. (1997). Letter-case specific priming in the right cerebral hemisphere with a form-specific perceptual identification task. Brain \& Cognition, 35, 239-258.

Caramazza, A., Laudanna, A., \& Romani, C. (1988). Lexical access and inflectional morphology. Cognition, 28, 297-332.

CARPENTER, G., \& GrossBerg, S. (1987). A massively parallel architecture for a self-organizing neural pattern recognition machine. Computer Vision, Graphics, \& Image Processing, 37, 54-115.

Carpenter, G., Grossberg, S., \& Reynolds, J. (1991). ARTMAP: Supervised real-time learning and classification of nonstationary data by a self-organizing neural network. Neural Networks, 4, 565-588.

CARR, T. H., \& Brown, J. S. (1990). Perceptual abstraction and interactivity in repeated oral readings: Where do they stand? Journal of Experimental Psychology: Learning, Memory, \& Cognition, 16, 731738.

Carroll, M., \& Kirsner, I. K. (1982). Context and repetition effects in lexical decision and recognition memory. Journal of Verbal Learning \& Verbal Behavior, 21, 55-69.

Challis, B. H., \& Roediger, H. L., III (1993). The effect of proportion overlap and repeated testing on primed word fragment completion. Canadian Journal of Experimental Psychology, 47, 113-123. 
ChurCh, B. A., \& SCHACTER, D. L. (1994). Perceptual specificity of auditory priming: Implicit memory for voice intonation and fundamental frequency. Journal of Experimental Psychology: Learning. Memory, \& Cognition, 20, 521-533.

COLTHEART, M. (1981). Disorders of reading and their implications for models of normal reading. Visible Language, 3, 245-286.

Coltheart, M. (1989). Implicit memory and the functional architecture of cognition. In S. Lewandowsky, J. C. Dunn, \& K. Kirsner (Eds.), Implicit memory: Theoretical issues (pp. 285-297). Hillsdale, NJ: Erlbaum.

Coltheart, M., Curtis, B., Atkins, P., \& Haller, M. (1993). Models of reading aloud: Dual route and parallel distributed processing approaches. Psychological Review, 100, 589-608.

Coslett, H. B., Roeltgen, D. P., Rothi, L. G., \& Heilman, K. M. (1987). Transcortical sensory aphasia: Evidence for subtypes. Brain \& Language, 32, 362-378.

CRAIK, F. I. M., \& Tulving, E. (1975). Depth of processing and the retention of words in episodic memory. Journal of Experimental Psychology: General, 104, 268-294.

Curran, T., Schacter, D. L., \& Bessenoff, G. (1996). Visual specificity effects in word stem completion: Beyond transfer appropriate processing? Canadian Journal of Experimental Psychology, 50, 22 33.

DAvis, C., \& ForSTER, K. I. (1994). Masked orthographic priming: The effect of prime-target legibility. Quarterly Journal of Experimental Psychology, 47A, 673-697.

DE Groot, A. M. B., \& NAS, G. L. J. (1991). Lexical representation of cognates and noncognates in compound bilinguals. Journal of Mem ory \& Language, 30, 90-123.

DONNELly, R. E. (1988). Priming across modality in implicit memory: Facilitation from auditory presentation to visual test of word-fragmen completion. Unpublished doctoral dissertation, University of Toronto.

DORFMAN, J. (1994). Sublexical components in implicit memory for novel words. Journal of Experimental Psychology: Learning, Memory, \& Cognition, 20, $1108-1125$.

Evetr, L. J., \& Humphreys, G. W. (1981). The use of abstract graphemic information in lexical access. Quarterly Journal of Experimental Psychology, 33A, 325-350.

Farah, M. J., Wilson, K. D., Drain, M., \& Tanaka, J. N. (1998). What is "special" about face perception? Psychological Review, 105, 482498.

Feldman, L. B., \& Moskovluevic, J. (1987). Repetition priming is not purely episodic in origin. Journal of Experimental Psychology: Learning, Memory, \& Cognition, 13, 573-581.

Feustel, T. C., Shiffrin, R. M., \& Salasoo, A. (1983). Episodic and lexical contributions to the repetition effect in word identification. Journal of Experimental Psychology: General, 112, 309-346

FORSTER, K. I. (1985). Lexical acquisition and the modular lexicon. Language \& Cognitive Processes, 1, 87-108.

FoRSTER, K. I. (1998). The pros and cons of masked priming. Journal of Psycholinguistic Research, 27, 203-233.

ForSTER, K. I., \& Davis, C. (1984). Repetition priming and frequency attenuation in lexical access. Journal of Experimental Psychology: Learning, Memory, \& Cognition, 10, 680-698.

Forster, K. I., \& Davis, C. (1991). The density constraint on formpriming in the naming task - Interference effects from a masked prime. Journal of Memory \& Language, 30, 1-25.

Forster, K. I., Davis, C., SChoknecht, C., \& Carter, R. (1987). Masked priming with graphemically related forms: Repetition or partial activation? Quarterly Journal of Experimental Psychology, 39A 211-251

FORSTER, K. I., \& GUESS, K. (1996). Effects of prime duration and visual degradation in masked priming. Paper presented at the 37th Annual Meeting of the Psychonomic Society, Chicago.

FranCIS, W. N., \& KuČERA, H. (1982). Frequency analysis of English usage: Lexicon and grammar. Boston: Houghton Mifflin.

Gerard, L. D., \& Scarborough, D. L. (1989). Language-specific lexical access of homographs by bilinguals. Journal of Experimental Psychology: Learning, Memory, \& Cognition, 15, 305-315.
GoldingER, S. D. (1998). Echoes of echoes? An episodic theory of lexical access. Psychological Review, 105, 251-279.

Goodale, M. A., Milner, A. D.. Jakobson, L. S., \& Carey, D. P (1991). A neurological dissociation between perceiving objects and grasping them. Nature, 349, 154-156.

Goshen-Gottstein, Y., \& Moscovitch, M. (1995a). Repetition priming for newly formed and preexisting associations: Perceptual and conceptual influences. Journal of Experimental Psychology: Learning, Memory, \& Cognition, 21, 1229-1248.

Goshen-GotTstein, Y., \& Moscovitch, M. (1995b). Repetition priming effects for newly formed associations are perceptually based Evidence from shallow encoding and format specificity. Journal of Experimental Psychology: Learning, Memory, \& Cognition, 21, $1249-1262$.

GraF, P., \& MANDLER, G. (1984). Activation makes words more accessible, but not necessarily more retrievable. Journal of Verbal Learning \& Verbal Behavior, 23, 553-568.

Graf, P., \& Schacter, D. L. (1985). Implicit and explicit memory for new associations in normal and amnesic patients. Journal of Experimental Psychology: Learning, Memory, \& Cognition, 11, 501-518.

Graf, P., \& Schacter, D. L. (1987). Selective effects of interference on implicit and explicit memory for new associations. Journal of Experimental Psychology: Learning, Memory, \& Cognition, 13, 385 395.

GraF, P., \& SChacter, D. L. (1989). Unitization and grouping mediate dissociations in memory for new associations. Journal of Experimental Psychology: Learning, Memory, \& Cognition, 15, 930-940.

Grainger, J., Cole, P., \& Segui, J. (1991). Masked morphological priming in visual word recognition. Journal of Memory \& Language, 30, 370-384

Grainger, J., \& Ferrand, L. (1994). Phonology and orthography in visual word recognition: Effects of masked homophone primes. Journal of Memory \& Language, 33, 218-233.

Grossberg, S. (1980). How does the brain build a cognitive code? Psychological Review, 87, 1-51.

Grossberg, S., Boardman, I., \& Cohen, M. (1997). Neural dynamics of variable speech categorization. Journal of Experimental Psychology: Human Perception \& Performance, 23, 481-514.

Grossberg, S., \& StONE, G. (1986). Neural dynamics of word recognition and recall: Attentional priming, learning, and resonance. Psychological Review, 93, 46-74.

HamanN, S., \& SQuire, L. (1997). Intact priming for novel perceptual representations in amnesia. Journal of Cognitive Neuroscience, $\mathbf{6}$, $699-713$

Henderson, L., Wallis, J., \& KNight, D. (1984). Morphemic structure and lexical access. In H. Bouma \& D. G. Bouhuis (Eds.), Attention and performance $X$ : Control of language processes (pp. 211 . 225). Hillsdale, NJ: Erlbaum.

HinTZMAN, D. L. (1986). Schema abstraction in a multiple trace model. Psychological Review, 93, 411-428.

Hummel, J. E., \& Biederman, I. (1992), Dynamic binding in a neural network for shape recognition. Psychological Review, 99, 480-517.

Hummel, J. E., \& STANKIEwicz, B. J. (1998). Two roles for attention in shape perception: A structural description model of visual scrutiny. Visual Cognition, 5, 49-79.

Humphreys, G. W., Besner, E., \& Quinlan, P. T. (1988). Event perception and the word repetition effect. Journal of Experimental Psychology: General, 117, 51-67.

Humphreys, G. W., EvetT, L. J., \& Quinlan, P. T. (1990). Orthographic processing in visual word identification. Cognitive Psychology, 22, 517-560.

JACKSON, A., \& MORTON, J. (1984). Facilitation of auditory word recognition. Memory \& Cognition, 12, 568-574.

JACOBY, L. L. (1983a). Perceptual enhancement: Persistent effects of an experience. Journal of Experimental Psychology: Learning. Memory, \& Cognition, 9, 21-38

JACOBY, L. L. (1983b). Remembering the data: Analyzing interactive processes in reading. Journal of Verbal Learning \& Verbal Behavior, $22,485-508$ 
JACOBY, L. L. (1991). A process dissociation framework: Separating automatic from intentional uses of memory. Journal of Memory \& Language, 30, 513-541.

JACOBY, L. L., \& DALLAS, M. (1981). On the relationship between autobiographical memory and perceptual learning. Journal of Experimental Psychology: General, 110, 306-340.

JACOBY, L. L., \& WITHERSPOON, D. (1982). Remembering without awareness. Canadian Journal of Psychology, 36, 300-324.

Kimura, D. (1973). The asymmetry of the human brain. Scientific American, 228, 70-78.

KIRSNER, K. (1973). An analysis of the visual component in recognition memory for verbal stimuli. Memory \& Cognition, 1, 449-453.

KirSNer, K., SMith, M. C., Lockhart, R. S., King, M. L., \& JAIN, M (1984). The bilingual lexicon: Language-specific units in an integrated network. Journal of Verbal Learning \& Verbal Behavior, $\mathbf{2 3}$ 519-539.

KirSnER, K., \& SpeElman, C. (1996). Skill acquisition and repetition priming: One principle, many processes? Journal of Experimental Psychology: Learning, Memory, \& Cognition, 22, 563-575.

Kolers, P. A., \& OstRY, D. J. (1974). Time course of loss of information regarding pattern analyzing operations. Journal of Verbal Learn ing \& Verbal Behavior, 13, 599-612.

Laudanna, A., Badecker, W., \& Caramazza, A. (1989). Priming homographic stems. Journal of Memory \& Language, 28, 531-546.

LIBERMAN, A. M. (1970). The grammars of speech and language. Cog nitive Psychology, 1, 301-323.

Liberman, A. M., \& Mattingly, I. G. (1985). The motor theory of speech perception revised. Cognition, 21, 1-36.

LoGAN, G. D. (1990). Repetition priming and automaticity: Common underlying mechanisms? Cognitive Psychology, 22, 1-35.

Lukatela, G., \& Turvey, M. T. (1994). Visual lexical access is initially phonological: 2 . Evidence from phonological priming by homophones and pseudohomophones. Journal of Experimental Psychology: General, 123, 331-353.

MACLEOD, C. (1989). Word context during initial exposure influences degree of priming in word fragment completion. Journal of Experimental Psychology: Learning, Memory, \& Cognition, 15, 398-406.

MARSOLEK, C. J. (1995). Abstract visual-form representations in the left cerebral hemisphere. Journal of Experimental Psychology: Human Perception \& Performance, 21, 375-386.

Marsolek, C. J. (1999). Dissociable neural subsystems underlie abstract and specific object recognition. Psychological Science, 10 111-118.

Marsolek, C. J., \& Burgund, E. D. (1997). Computational analyses and hemispheric asymmetries in visual-form recognition. In $\mathrm{S}$. Christman (Ed.), Cerebral asymmetries in sensory and perceptual processing (pp. 125-158). Amsterdam: Elsevier.

Marsolek, C. J., Kosslyn, S. M., \& Squire, L. R. (1992). Formspecific visual priming in the right cerebral hemisphere. Journal of Experimental Psychology: Learning. Memory, \& Cognition, 18, 492508.

Marsolek, C. J., Schacter, D. L., \& Nicholas, C. D. (1996). Formspecific visual priming for new associations in the right cerebra hemisphere. Memory \& Cognition, 24, 539-556.

Marsolek, C. J., Squire, L. R., Kosslyn, S. M., \& Lulenski, M. E. (1994). Form-specific explicit and implicit memory in the right cerebral hemisphere. Neuropsychology, 8, 588-597.

MASSON, M. E. J. (1986). Identification of typographically transformed words: Instance-based skill acquisition. Journal of Experimental Psychology: Learning, Memory, \& Cognition, 12, 479-488.

Masson, M. E. J., \& Freedman, L. (1990). Fluent identification of repeated words. Journal of Experimental Psychology: Learning, Memory, \& Cognition, 16, 355-373.

Masson, M. E. J., \& MacLeOd, C. M. (1992). Re-enacting the route to interpretation: Enhanced perceptual identification without prior perception. Journal of Experimental Psychology: General, 121, 145176

Masson, M. E. J., \& MaCLeon, C. M. (1996). Contributions of processing fluency to repetition effects in masked word identification. Canadian Journal of Experimental Psychology, 50, 9-21.

MCClelland, J. L. (1976). Preliminary letter identification in the per- ception of words and nonwords. Journal of Experimental Psychol ogy: Human Perception \& Performance, 3, 80-91.

McClelland, J. L., \& RumelhaRT, D. E. (1981). An interactive mode of context effects in letter perception: Part I. An account of basic findings. Psychological Review, 88, 375-405.

MCClelland, J. L., \& Rumelhart, D. E. (1986). A distributed model of human learning and memory. In J. L. McClelland, D. E. Rumelhart, \& the PDP Research Group (Eds.), Parallel distributed processing: Explorations in the microstructure of cognition. Vol. 2. Psychological and biological models (pp. 170-215). Cambridge, MA: MIT Press.

McConKIE, G. W., \& ZoLA, D. (1979). Is visual information integrated across successive fixations in reading? Perception \& Psychophysics, 25, 221-224

McKoon, G., \& RatclifF, R. (1979). Priming in episodic and semantic memory. Journal of Verbal Learning \& Verbal Behavior, 18, 463-480.

Medin, D. L., \& SChaffer, M. M. (1978). Context theory of classification learning. Psychological Review, 85, 207-238.

Micco, A., \& MAsson, M. E. J. (1991). Implicit memory for new associations: An interactive process approach. Journal of Experimental Psychology: Learning, Memory, \& Cognition, 17, 1105-1123.

MORTON, J. (1979). Facilitation in word recognition: Experiments causing change in the logogen model. In P. A. Kolers, M. E. Wrolstad, \& $\mathrm{H}$. Bouma, Processing models of visible language (pp. 259-268). New York: Plenum.

Moscovitch, M. (1992). Memory and working-with-memory-A component process model based on modules and central systems. Journal of Cognitive Neuroscience, 4, 257-267.

Moscovitch, M., Winocur, G., \& Mclachlan, D. (1986). Memory as assessed by recognition and reading time in normal and memory impaired people with Alzheimer's disease and other neurological disorders. Journal of Experimental Psychology: General, 115, 331-346

Mozer, M. C. (1989). Types and tokens in visual letter perception. Journal of Experimental Psychology: Human Perception \& Performance, 15, 287-303.

Musen, G., \& SQuiRe, L. R. (1993). On the implicit learning of novel associations by amnesic patients and normal subjects. Neuropsychology, 2, 119-135.

NappS, S. E., \& Fowler, C. A. (1987). Formal relationships among words and the organization of the mental lexicon. Journal of Psycholinguistic Research, 16, 257-272.

Neely, J. H., \& DurgunoĞLu, A. Y. (1985). Dissociative episodic and semantic priming effects in episodic recognition and lexical-decision tasks. Journal of Memory \& Language, 24, 446-489.

NoRRIS, D. (1995). Signal detection theory and modularity: On being sensitive to the power of bias models of semantic priming. Journal of Experimental Psychology: Human Perception \& Performance, 21, 935-939.

OLIPHANT, G. W. (1983). Repetition and recency effects in word recognition. Australian Journal of Psyehology, 35, 393-403.

PaAP, K. R., Newsome, S. L., McDonald, J. E., \& SchVaneVeldt, R. W. (1982). An activation-verification model for letter and word recognition. Psychological Review, 89, 573-594.

Peterson, S. E., Fox, P. T., Posner, M. I., Mintun, M., \& Raichle, M. E. (1989). Positron emission tomographic studies of the processing of single words. Journal of Cognitive Neuroscience, 2, 320343.

Plaut, D. C., McClelland, J. L., Seidenberg, M. S., \& Patterson, K. (1996). Understanding normal and impaired word reading: Computational principles in quasi-regular domains. Psychological Review, 103, 56-115.

Poldrack, R. A., Selco, S. L., Field, J. E., \& Cohen, N. J. (1999). Journal of Experimental Psychology: Learning. Memory, \& Cognition, 25, 208-235.

POLK, T. A., \& FARAH, M. J. (1997). A simple common contexts explanation for the development of abstract letter identities. Neural Computation, 9, 1277-1289.

RaAismakers, J. G. W., Schooler, L., \& Shiffrin, R. M. (1997, November). Effects of repeated study on word identification in a $2 A F C$ task. Paper presented at the annual meeting of the Psychonomic Society, Philadelphia. 
Rajaram, S., \& Neely, J. H. (1992). Dissociative masked repetition priming and word-frequency effects in lexical decision and episodic recognition tasks. Journal of Memory \& Language, 31, 152-182.

Rajaram, S., \& RoEDiger, H. L., III (1993). Direct comparison of four implicit memory tests. Journal of Experimental Psychology: Learning, Memory, \& Cognition, 19, 765-776.

Ratcliff, R., \& McKoon, G. (1997). A counter model for implicit priming in perceptual word identification. Psychological Review, 104, 319-343.

RAYNER, K., MCCONKIE, G. W., \& ZoLA, D. (1980). Integrating information across eye movements. Cognitive Psychology, 12, 206226.

Rayner, K., \& Sereno, S. C. (1994). Eye movements in reading: Psycholinguistic studies. In M. A. Gernsbacher (Ed.), Handbook of psycholinguistics (pp. 57-81). New York: Academic Press.

Reingold, E. M., \& Goshen-Gottstein, Y. (1996a). Automatic retrieval of new associations under shallow encoding conditions. Consciousness \& Cognition, 5, 117-130.

Reingold, E. M., \& Goshen-GotTstein, Y. (1996b). Separating consciously controlled and automatic influences in memory for new associations. Journal of Experimental Psychology: Learning, Memory, \& Cognition, 22, 397-406.

RoEdiger, H. L., III (1990). Implicit memory: Retention without remembering. American Psychologist, 45, 1043-1056.

RoEDIGER, H. L., III, \& BlaxTON, T. A. (1987). Effects of varying modality, surface features, and retention interval on priming in wordfragment completion. Memory \& Cognition, 15, 379-388.

ROEDIGER, H. L., III, \& Challis, B. H. (1992). Effects of exact repetition and conceptual repetition on free recall and rimed word-fragment completion. Journal of Experimental Psychology: Human Learning \& Memory, 18, 3-14.

RoEDiger, H. L., III, \& MCDERMOTt, K. B. (1993). Implicit memory in normal human subjects. In F. Boller \& J. Grafman (Eds.), Handbook of neuropsychology (Vol. 8, pp. 63-131). New York: Elsevier.

ROEDIGER, H. L., III, \& WELDON, M. S. (1987). Reversing the picture superiority effect. In M. A. McDaniel \& M. Pressley (Eds.), Imagery and related mnemonic processes: Theories, individual differences, and applications (pp. 151-174). New York: Springer-Verlag.

Roediger, H. L., III, Weldon, M. S., Stadler, M. A., \& Riegler, H. G. (1992). Direct comparison of word stems and word fragments in implicit and explicit retention tests. Journal of Experimental Psychology: Learning, Memory, \& Cognition, 18, 1251-1269.

RUECKL, J. G., \& DROR, I. I. (1994). The effect of orthographic-semantic systematicity on the acquisition of new words. In C. Umiltà \& M. Moscovitch (Eds.), Attention and performance XV: Conscious and nonconscious information processing (pp. 571-588). Cambridge, MA: MIT Press.

RueckL, J. G., \& Olds, E. M. (1993). When pseudowords acquire meaning: Effect of semantic associations on pseudoword repetition priming. Journal of Experimental Psychology: Learning, Memory, \& Cognition, 19, 515-527

RYNARD, D., \& BESNER, D. (1987). Basic processes in reading: On the development of cross-case letter matching without reference to phonology. Bulletin of the Psychonomic Society, 25, 361-363.

Salasoo, A., \& ShIFFrIN, R. M. (1985). Building permanent memory codes: Codification and repetition effects in word identification. Journal of Experimental Psychology: General, 114, 50-77.

Scarborough, D. L., Cortese, C., \& Scarborough, H. S. (1977). Frequency and repetition effects in lexical memory. Journal of Experimental Psychology: Human Perception \& Performance, 3, 1-17.

SCHACTER, D. L. (1990). Perceptual representation system and implicit memory: Toward a resolution of the multiple memory debate. In A. Diamond (Ed.), Development and netural basis of higher cognitive function (Annals of the New York Academy of Sciences, Vol. 608, pp. 543-571). New York: New York Academy of Sciences.

SChacter, D. L. (1994). Priming and multiple memory systems: Perceptual mechanisms of implicit memory. In D. L. Schacter \& E. Tulving (Eds.), Memory systems 1994 (pp. 233-268). Cambridge, MA: MIT Press.

SChacter, D. L., \& Graf, P. (1986). Effects of elaborative processing on implicit and explicit memory for new associations. Journal of Experimental Psychology: Learning, Memory, \& Cognition, 12, 432-444.
Schacter, D. L., \& Graf, P. (1989). Modality specificity of implicit memory for new associations. Journal of Experimental Psychology: Learning, Memory, \& Cognition, 15, 3-12.

Schacter, D. L., McGlynn, S. M., Mrlberg, W. P., \& Church, B, A (1993). Spared priming despite impaired comprehension: Implicit memory in a case of word meaning deafness. Neuropsychology, 7 , 107-118.

Segui, J., \& Grainger, J. (1990). Priming word recognition with orthographic neighbors: Effects of relative prime-target frequency Journal of Experimental Psychology: Human Perception \& Performance, 16, 65-76.

Seidenberg, M. S., \& MCClelland, J, L. (1989), A distributed, developmental model of word recognition and naming. Psychological Review, 96, 523-568.

Sloman, S. A., Hayman, C. A. G., Ohta, N., LaW, J., \& Tulving, E. (1988). Forgetting in primed fragment completion. Journal of Experimental Psychology: Learning, Memory, \& Cognition, 14, 223-239.

Smith, M. C., MacLeod, C. M., Bain, J. D., \& Hoppe, R. B. (1989). Lexical decision as an indirect test of memory: Repetition and listwide priming as a function of type of encoding. Journal of Experimental Psychology: Learning, Memory, \& Cognition, 15, $1109-1118$

StOLz, J. A., \& BESNER, D. (1998). Levels of representation in visual word recognition: A dissociation between morphological and semantic processing. Journal of Experimental Psychology: Human Perception \& Performance, 24, 1642-1655.

Stolz, J. A., \& Feldman, L. B. (1994). The role of orthographic and semantic transparency of the base morpheme in morphological processing. In L. B. Feldman (Ed.), Morphological aspects of language processing: Cross-linguistic perspectives (pp. 109-129). Hillsdale, $\mathrm{NJ}$ : Erlbaum

TAFT, M., \& Forster, K. 1. (1975). Lexical access and retrieval of prefixed words. Journal of Verbal Learning \& Verhal Behavior, 14, 638 649.

TARR, M. J., \& BüLTHOFf, H. H. (1998). Image-based object recognition in man, monkey and machine. Cognition, 67, $1-20$

TENPENNY, P. L. (1995). Abstractionist versus episodic theories of repetition priming and word identification. Psychonomic Bulletin \& Review, 2, 339-363

Tulving, E., \& SCHacter, D. L. (1990). Priming and human memory systems. Science, 247, 301-306.

VAN LanCKer, D., \& Kreiman, J. (1987). Voice discrimination and recognition are separate abilities. Neuropsychologia, 25, 829-834.

VRIEZEn, E. R., Moscovitch, M., \& Bellos, S. A. (1995). Priming effects in semantic classification tasks. Journal of Experimental P $P y$ chology: Learning, Memory, \& Cognition, 21, 933-946.

Warrington, E. K., \& Weiskrantz, L. (1974). The effect of prior learning on subsequent retention in amnesic patients. Neuropsychologia, 12, 419-428.

WhITLOW, J. W., JR. (1990). Differential sensitivity of perceptual identification for words and pseudowords to test expectations: Implications for the locus of word frequency effects. Journal of Experimental Psychology: Learning, Memory, \& Cognition, 16, 837-851.

Whittlesea, B. W. A., \& Brooks, L. R. (1988). Critical influence of particular experiences in the perception of letters, words, and phrases. Memory \& Cognition, 16, 387-399.

Whittlesea, B. W. A., \& Cantwell, A. L. (1987). Enduring influence of the purpose of experiences: Encoding-retrieval interactions in word and pseudoword perception. Memory \& Cognition, 15, 465472 .

Zatorre, R. J., Evans, A. C., Meyer, E., \& Gjedde, A. (1992). Lateralization of phonetic and pitch discrimination in speech processing. Science, 256, 846-849.

\section{NOTES}

1. Note that although priming for low-frequency words is not eliminated when different semantic decisions are performed at study and test, priming effects are reduced, as documented by Vriezen et al. (1995), among others. It should be noted, however, that reduced priming following a change in task is consistent with an abstractionist approach. From the abstractionist perspective, priming is a function of repeated access to preexisting abstract codes, and accordingly, priming is re- 
duced to the extent that the study and test tasks are mediated by different sets of representations (at the extreme, when tasks do not rely on any shared representations, no priming should be expected). Such an approach is clearly articulated by Coltheart (1989) and is consistent with the general component processing framework (e.g., Moscovitch, 1992).

2 . It should be noted that changes in discriminability do not necessarily imply improved perceptual processing, as noted by Norris (1995) Indeed, Masson and MacLeod (1996) argued against the view that priming reflects an improvement in perceptual processing, despite the consistent tendency for a change in $d^{\prime}$ in their own studies.

3. A few studies have attempted to relate long-term priming to learning (e.g., Kirsner \& Speelman, 1996; Logan, 1990; Poldrack, Selco, Field, \& Cohen, 1999). Indeed, one finding reported by Kirsner and Speelman seems to challenge the view that priming is a by-product of learning. The authors found the benefit associated with studying a word in an experiment was much larger than would be expected from incrementing the number of preexperimental exposures by one. That is, the authors estimated the number of times low-, medium-, and high-frequency words were read by an average 22 -year-old reader, and then in a lexica decision task, measured response latencies and error rates to these items in order to estimate the improvement associated with a single preexperimental exposure to a word. This benefit was much smaller than the improvement they observed when repeating words within the experiment, indicating that a preexperimental encounter with a word cannot support robust experimental priming effects.

However, there are ways to reconcile this finding with the view adopted here. For example, it is important to note that words encountered outside the laboratory tend to be read in the context of sentences, and, as noted earlier, this might reduce the amount of attention devoted to the perceptual encoding of the word. Thus, if orthographic learning is related to the amount of attention that is directed to this level (consistent with Grossberg \& Stone, 1986), then many preexperimental encounters with words would have had a relatively small impact on learning relative to the laboratory setting, in which words are read out of context. There are other possible ways to reconcile the present account of priming with these findings as well. For example, Poldrack et al. (1999) recently described two computational models in which the Kirsner and Speelman (1996) results are replicated within a model in which priming and learning reflect the same processes.

(Manuscript received October 15, 1998; revision accepted for publication May 20,1999.) 